\title{
Assessment and Design of Illumination in the Unit of Carbon Dioxide Gas of Khuzestan Zam Zam Company
}

\author{
Hossein Ali Rangkooy ${ }^{1, *}$; Arezoo Zangeneh ${ }^{2}$; Amin Lefti ${ }^{1}$ \\ ${ }^{1}$ Department of Occupational Health, Faculty of Health, Ahvaz Jundishapur University of Medical Sciences, Ahvaz, IR Iran \\ ${ }^{2}$ Department of Environmental Engineering Air pollution, Faculty of Environmental Engineering, Khuzestan Science and Research Branch,Islamic Azad University, Ahvaz, IR Iran \\ ${ }^{*}$ Corresponding author: Hossein Ali Rangkooy, Department of Occupational Health, Faculty of Health, Ahvaz Jundishapur University of Medical Sciences, Ahvaz, IR Iran. Tel: +98-6133738269, \\ Fax:+98-6133738282, E-mail: rangkooy@gmail.com
}

Received: February 1, 2015; Accepted: March 15, 2015

Background: Light is the first that necessary for any effort. This factor, more than any physical variable, affects human labor. Two properties of cognitive and psychological lighting in the workplace can affect human performance.

Objectives: This study aimed to assess the illuminance in $\mathrm{CO}_{2}$ Gas unit of Khuzestan Zam Zam Company, and resolve its light deficiency through artificial lighting design.

Materials and Methods: This study is a descriptive-analytical based on survey of natural and artificial lighting sources in the workplace. It also included measurement of lighting levels in 3 shifts, calculating the average illuminance and comparing with recommended values, drawing graphs of results measured illuminance, and finally designing the lighting of the unit by lumen method with room index (Kr). The study was conducted between March and June 2006 and its data were analyzed with 1-way analysis of variance (ANOVA).

Results: Mean \pm SD level of illuminance in the morning, evening, and night was $211.31 \pm 292.07,182.16 \pm 205.16,67.47 \pm 71.10$ (lx), respectively. The results showed that there is a significant difference $(\mathrm{P}<0.001)$ between average illuminance of 3 shifts of morning (day light), evening, and night (artificial light) and the standard illuminance value (300 lx), which entails the lighting design's work area for this unit. According to the design of artificial lighting base on the lumen method calculations in $\mathrm{CO}_{2}$ Gas unit, 400,250 watt Metal Halides and 10585 watt compact fluorescent lamps were required, which their numbers were 610 and 44 , respectively.

Conclusions: This paper considered the method based on comprehensive surveys of workplace illuminance levels (natural light and artificial light) and design of lighting system as one of workplace physical factors in order to increase the efficiency of the production unit, decrease in carelessness, fatigue errors, and work accident.

Keywords: Illuminance Assessment; Lighting; Work Place

\section{Background}

Light is one of the most important factors for observation. This factor, more than any other physical variable affects workers. Both cognitive and psychological properties of lighting in the workplace can affect human performance (1-6).

Adequate lighting has preventive measures of incidents that happen due to fatigue. Research has shown an association between work production and sufficient brightness, which leads to the higher quality of products. Welldesigned lighting decreases the number of occupational accidents (7). Researchers have suggested a number of work design strategies in order to enhance the quality of work (8). However, little attention has been paid the actual process of work design (9).

Improper design of lighting systems leads to insufficient accuracy at work with faulty outcomes as fatigue, headache, visual impairment, which causes accidents or some light glare and eye injury $(3,4)$.

Improving the lighting at work place has several positive effects on the performance of the works; lighting influences productivity factors such as output, errors, and accidents (10). Many field studies in industrial environments have shown large increases in productivity when the lighting level has been enhanced (11). For good lighting practice, in addition to the required illuminance, qualitative and quantitative aspects are satisfied as well $(2,12-15)$.

\section{Objectives}

Considering the importance of the relationship between production and lighting and the required lighting according to type of workplace, we assessed and evaluated the average illumination in 3 work shifts of $\mathrm{CO}_{2}$ Gas unit of Khuzestan Zam Zam Company and then these values were compared to the national standard values.

\section{Materials and Methods}

This study is a descriptive-analytical one. Measurement

Copyright (C) 2015, Ahvaz Jundishapur University of Medical Sciences. This is an open-access article distributed under the terms of the Creative Commons Attribution-Non Commercial 4.0 International License (http://creativecommons.org/licenses/by-nc/4.0/) which permits copy and redistribute the material just in noncommercial usages, provided the original work is properly cited. 
scale used in this study (distance - the ratio), and comparison of the measured data with 1-way analysis of variance (ANOVA) were performed between March and June 2006. Descriptive statistics was used for examining the average and standard deviation of measured amounts of illuminance in the 3 shifts. In order to assess the illuminance of $\mathrm{CO}_{2}$ Gas unit of Khuzestan Zam Zam Company, we examined the light utility unit aspect of lighting design position, type of lights, sort of lamps and position of them, and the number of doors and windows (Natural and Artificial lighting).

The next step involves preparation of a workshop map, by dividing the workplace and measuring stations; the illuminance level in the center of each station and the average illuminance per shift was calculated and compared with the standard values (16-20). Recommended lighting levels for different parts of the soft drink industry were 200 - 300 lx. Measuring total lighting intensity unit of $\mathrm{CO}_{2}$ was carried out by measuring the illumination levels (in Lux) of each shift using a calibrated Lux meter TES1334 model (TES Electrical Electronic Corp, Taiwan) in a horizontal plane at a height of $75 \mathrm{~cm}$ from the floor. For comparing the amount of measured lighting intensity (natural and artificial lighting) to the standard levels, the standards of technical committee of occupational health, Iran management office of work and environment health announced 2002, 2nd edition, were used, which were according to the Standards of Lighting Engineering Association of North America (21). All data were analyzed by using SPSS software (Chicago, IL, USA, version 20.0, SPSS Inc.).

One of the methods of measurement and evaluation of artificial lighting system is measuring general lighting on a grid that is used in the enclosed places and buildings. According to Illuminating Engineering Society (IES) method, in order to determine the average amount of lighting intensity in a horizontal plane, workplace is divided to squares by the length of 1 meter and in this way, 122 points were determined as the station in the map.

In order to calculate the average illuminance in 3 shifts of morning (day light), evening, and night (artificial light), the illuminance at the center of each station and the average illuminance were calculated through dividing the total illuminance in each shift by the number of the desired stations (22-24). Golden Software Surfer, version 9.0 was used to draw graphs of measured illuminance results. To calculate the number of lamps in lumen illumination method, we need the room index (Kr); coefficients of reflection (Coefficient of Reflectance Floor [ $\rho \mathrm{fc}$ ], Coefficient of Reflectance Ceiling [ $\rho c c]$, Coefficient of Reflectance Walls [ $\rho \mathrm{w}])$; the maximum allowable distance between the lamps (MH), depending on installation height from floor lamps or ceiling to floor height and Distribution curve of the lamp and sort reflector; coefficient of utilization, maintenance factor; and unit area and luminous flux of each lamp (IES tables). Then, the number of lamps can be calculated by Equation 1 :
1)

$N=\frac{\mathrm{Qt}}{\mathrm{QL}}$

Where N is the number of lamp, Qt is total luminous flux, and QL is luminous flux of lamp.

In order to determination the total luminous flux and the Average Illumination, Equation 2 is used:

$$
E_{\mathrm{Av}}=\frac{\text { Qt.CU.MF }}{A}
$$

Where Qt is luminous flux of lamps (lumen), MF is Maintenance Factor, CU is Coefficient of Utilization where, A is Unit Area $\left(\mathrm{m}^{2}\right), \mathrm{E}_{\mathrm{Av}}$ is the average illumination, and LUX (lumen $/ \mathrm{m}^{2}$ ).

Also, the distance between the lamps (X) with length (L) and width (W) and the number of lamps (N) were calculated and determined (3,16-19).

\section{Results}

General lighting of $\mathrm{CO}_{2}$ Gas unit Khuzestan Zam Zam Company was provided by a window as the natural source and a metal halide bulb and gas lamp as only source of artificial lighting so that not only arrangement and uniformity of light distribution were not desirable but also their design and installation were not appropriate. The results from measuring the average illumination in 3 shifts, morning, evening, and night in are presented in Table 1 . Based on the comparison of average illuminance of 3 shifts with standard (300 lx), the average lighting of morning, evening, and night shifts in one day were $88.68,117.11$, and 232.56 lux, respectively, which all of them were less than standard.

One-way ANOVA was used to compared the average illuminance of 3 shifts, morning (day light), evening, and night (artificial light) with standard illuminance (300 lx). According to this test $(\mathrm{P}<0.001)$, which represents a significant difference between 3 shifts with the standard value, this unit needs a lighting redesign. Graphical displays of the illuminance level in 3 shifts are presented in Figures 1, 2, and 3. In order to avoid the influence of daylight in the calculations of artificial lighting, only average illumination of night shifts was considered, which its rate of $232.56 \mathrm{~lx}$ was less than the standard. Therefore, the shortage of lighting should be provided by design with lumen method. Rate of room index, coefficient of utilization, maintenance factor, and other parameters were calculated to determine the total luminous flux and lamp numbers based on the lumen method (Table 2).

Because Metal halide lamps have appropriate color close to natural light, adequate useful life, and industrial applications, they were recommended for Gas units. 
Rangkooy HA et al.

\begin{tabular}{lccccc}
\hline Table 1. Measured Illuminance Levels in 3 Shifts of Morning (Natural Light), Evening, and Night (Artificial Light) a Day \\
\hline Measurement Time per Shift & Recommended Illuminance, lx & \multicolumn{4}{c}{ Measured Illuminance, lx } \\
\cline { 3 - 6 } & & Mean \pm SD & Min - Max & Median & Mode \\
\hline Morning shift (natural light) & 300 & $211.31 \pm 292.07$ & $30-1923$ & 148 & 163 \\
Evening shift & 300 & $182.16 \pm 205.16$ & $11-1431$ & 130 & 142 \\
Night shift (artificial light) & 300 & $67.44 \pm 71.10$ & $3-656$ & 40 & 9 \\
\hline
\end{tabular}

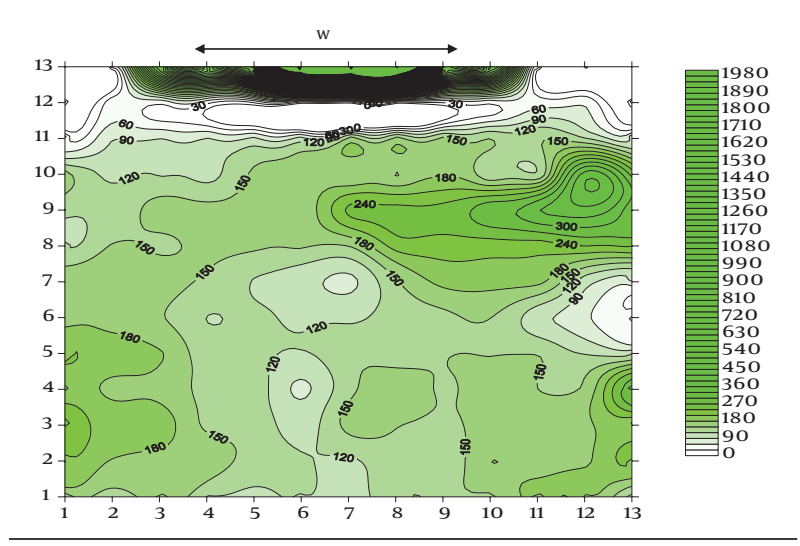

Figure 1. Graphical Display the Illuminance Measurements in Morning $\underline{\text { Shift With a Natural Daylight Source (a Window) }}$

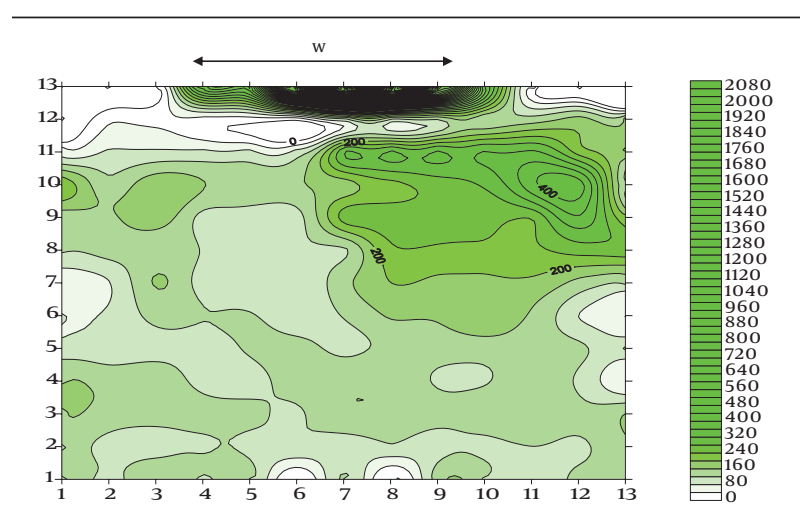

Figure 2. Graphical Display the Illuminance Measurements in Evening Shift With a Natural Daylight Source (a Window)

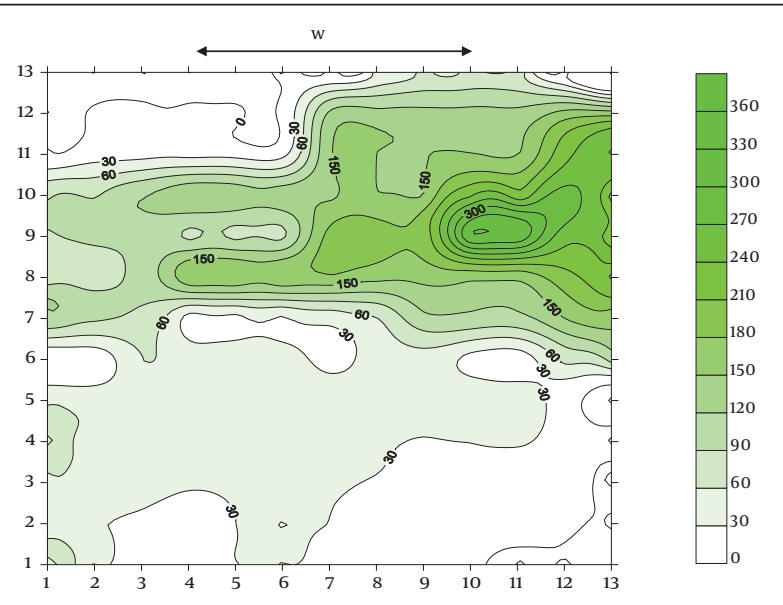

$\overline{\text { Figure 3. Graphical Display the Illuminance Measurements in Night Shift }}$ With Artificial Lighting Source
Table 2. Lighting Calculations Based on Lumen Method With Using Room Index ${ }^{a}$

\begin{tabular}{lc}
\hline Room index & Value \\
\hline L & $14.77^{\mathrm{b}}$ \\
\hline $\mathbf{H}$ & $13.70^{\mathrm{b}}$ \\
\hline MH & $5.5^{\mathrm{b}}$ \\
\hline$\rho \mathbf{c C}$ & $5.5^{\mathrm{b}}$ \\
\hline fC & $50^{\mathrm{c}}$ \\
\hline$\rho \mathbf{W}$ & $15^{\mathrm{c}}$ \\
\hline Kr & $80^{\mathrm{c}}$ \\
\hline CU & 1.29 \\
\hline CUc & 0.54 \\
\hline MF & 0.56 \\
\hline
\end{tabular}

a Abbreviations: $\mathrm{CU}$, coefficient of utilization; CUC, coefficient of Utilization Corrected; H, Height; Kr, Room index; L, Length; MF, maintenance factor; $\mathrm{MH}$, maximum allowable distance between the lamps; W, width; $\rho c c$, coefficient of reflectance ceiling; $\rho f c$, coefficient of reflectance Floor; $\rho w$, coefficient of reflectance walls.

b Data are presented as $\mathrm{m}$.

c Data are presented as \%.

$\mathrm{d}$ For direct light, semi-direct and same distribution.

Color rendering index of these lamps have good color expressions and do not produce much heat in types of $400 \mathrm{~W}$ or $250 \mathrm{~W}$. In order to produce natural light as daylight, a mixture of yellow and white light was used, so that the amount of yellow and white light luminous flux were 10\% Qt and 90\% Qt, respectively. Table 3 shows lighting calculations of lamps.

A $400 \mathrm{~W}$ Metal Halide lamp the luminous efficiency is 32000 lumens flux per watt and a $250 \mathrm{~W}$ Metal Halide lamp the luminous efficiency is 17000 lumens flux per watt. The required numbers of 400 and 250 watt Metal Halide lamps are obtained by dividing the total luminous flux by each lamp's luminous flux, which are found as 6 and 10 lamps, respectively. Also, the yellow compact fluorescent lamp luminous efficiency of $150 \mathrm{~W}$ and $85 \mathrm{~W}$ are 6500 and 5100 lumens per watt, respectively, which is equal to 4 lamps. The calculations of the choice of $400 \mathrm{~W}$ and $250 \mathrm{~W}$ metal halide lamps are presented in Table 4. 
Rangkooy HA et al.

Table 3. Lighting Calculations of Lamps ${ }^{\text {a }}$

\begin{tabular}{|c|c|c|c|c|c|c|c|}
\hline & \multirow[t]{2}{*}{ Qt } & \multirow[t]{2}{*}{ Yellow Luminous Flux ${ }^{b}$} & \multirow[t]{2}{*}{ White Luminous Flux ${ }^{\text {b }}$} & \multicolumn{2}{|c|}{ Metal Halide, $\mathrm{W}^{\mathrm{c}}$} & \multicolumn{2}{|c|}{ Yellow CLF, $\mathrm{W}^{\mathrm{C}}$} \\
\hline & & & & 400 & 250 & 105 & 85 \\
\hline Value, Im & 197093.1818 & $19709 / 31818$ & $177383 / 8636$ & $32000(6)$ & $17000(10)$ & $6500(4)$ & $5100(4)$ \\
\hline
\end{tabular}

Table 4. 400 and 250 Watt Metal Halide Lamp's Calculations ${ }^{a}$

\begin{tabular}{lc}
\hline Title & Value \\
\hline QL400, W(lumens flux per watt) & 32000 \\
QL250, W(lumens flux per watt) & 17000 \\
NL400, W(lamp) & 6 \\
\hline NL250, W(lamp) & 10 \\
\hline EAv, lX & 300 \\
MH, m & 5.5 \\
X1, m & 4.49 \\
X2, m & 7.38 \\
X3, m & 3.74 \\
X4, m & 4.9 \\
\hline a Abbri
\end{tabular}

a Abbreviations: $\mathrm{E}_{\mathrm{Av}}$, average illumination; $\mathrm{MH}$, maximum allowable distance between the lamps; QL, luminous flux of lamp; X1, distance between $400 \mathrm{~W}$ Metal halide lamps and 105 W CLF lamps; X2, distance between 400 watt metal halide lamps; X3, Distance between $250 \mathrm{~W}$ metal halide lamps and 85 W CLF lamps; X4, Distance between 250 watt metal halide lamps.

\section{Discussion}

Based on the average illumination measured in $\mathrm{CO}_{2}$ gas unit per each shift and its comparison with the standard level (300 lx), the average light of morning, evening, and night shifts in one day, was $88.68,117.11$, and $232.56 \mathrm{~lx}$, respectively which were less than the standard level. Results of this study are in agreement with study that was performed in dormitory halls of Isfahan University of Medical Sciences, Iran (25). A similar study was conducted in which 3 different illumination levels were evaluated (450 lx; 1,100 lx; 1,500 lx) (26). Also, the result of this study is in line with the assessment of illuminance levels in automotive assembly industry in 2013 (21) and illuminance measurements in 3 packing plants in Saveh (27). In another study by Espinoza et al. at the University of Costa Rica, in 2010, it was found that half of the measuring stations were poorly lit (28). According to this research, the worker is not allowed to work only with a local lighting source, but his surroundings have to be lit additionally with general lighting sources (at least $10 \%$ of the total lighting of the room), otherwise the probability of accidents rises (29). Therefore, the lighting appropriate with this unit was designed with lumen method that based on it, the number of $400 \mathrm{~W}, 250 \mathrm{~W}$ metal halide lamps and
$105 \mathrm{~W}$ and $85 \mathrm{~W}$ compact fluorescent lamps required for lighting units of $\mathrm{CO}_{2}$ Gas Zam Zam Company were 6, 10 and 4,4, respectively. Also, metal halide lamp had appropriate color close to natural day light. The maximum allowable distance between optional $400 \mathrm{~W}$ metal halide lamps is $5.5 \mathrm{~m}$ and the distance between $400 \mathrm{~W}$ Metal Halide lamps and $105 \mathrm{~W}$ yellow compact fluorescent lamp is $4.49 \mathrm{~m}$.

This paper considers the solution based on the study of lighting level in one of the production units of a plant food. Because of the poor design and insufficient lighting, the required lighting appropriate for the production site was provided by artificial light system. Through comprehensive surveys on workplace illuminance levels (daylight and artificial light) and design of lighting system (as one of the physical factors in the work place), the efficiency of the production increases and on the other hand, fatigue errors and carelessness, as well as work accidents decrease.

\section{Acknowledgements}

The authors would like to appreciate the help of Zam Zam personnel and all people who assisted on the implementation of this research.

\section{Authors' Contributions}

Hossein Ali Rangkooy: research concept and design, data analysis and interpretation, writing the article, critica revision of the article, and its final approval; Arezoo Zangeneh and Amin Lefti: collection and analysis of the data.

\section{Funding/Support}

This study was supported by the research deputy of Ahvaz Jundishapur University of Medical Sciences (Registration No.85S.60).

\section{References}

1. Kakooei H, Zakerian SA. ighting for Health and Safety. 1st edTehran University of medical sciences faculty of research publication of fice: Tehran; 2010.

2. Smith NA. Lighting for Health and Safety.London: ButterworthHeinemann; 2000 .

3. Kalhor H. Illuminating Engineering. 1st edTehran: Publication Company; 1986.

4. Moon PH. The Scientific Basis of Illuminating Engineering.New York: McGraw-Hill; 1961.

5. Harms-Ringdahl L. Safety Analysis: Principles and Practice in Occupational Safety. 2nd edLondon: Taylor and Francis; 2003. 
6. Mike A. Visual workplace: How you see performance in the planet and in the office. Int J Financ Trade. 2010;11(3):250-60.

7. Chandrasekar K. Workplace environment and its impact on organisational performance in public sector organisations. Int $J$ Enterp Comput Bus Syst. 2011;1(1).

8. Nadin SJ, Waterson PE, Parker SK. Participation in job redesign: An evaluation of the use of a sociotechnical tool and its impact. Hum Fact Ergonom Manuf Serv Ind. 2001;11(1):53-69.

9. Oldham GR. Job Design. In: Cooper CL, Robertson IT editors. International Review of Industrial and Organizational Psychology. 11th ed. New York: John Wiley \& Sons Inc;1996. pp. 33-60.

10. Henri J, Ariodne T. Mechanisms involved in enhancing human performance by changing the lighting in the industrial workplace. Int J Ind Ergonom. 2005;35(9):843-55.

11. Juslen HT, Wouters MC, Tenner AD. Preferred task-lighting levels in an industrial work area without daylight. Lighting Res Technol. 2005;37(3).

12. Eklund NH, Boyce PR, Simpson SN. Lighting and sustained performance: modeling data-entry task performance. J Illuminating Eng Soc. 2001;30(2):126-41.

13. Fontoynont M. Perceived performance of daylighting systems: lighting efficacy and agreeableness. Sol Energy. 2002;73(2):83-94.

14. Helland M, Horgen G, Kvikstad TM, Garthus T, Bruenech JR, Aaras A. Musculoskeletal, visual and psychosocial stress in VDU operators after moving to an ergonomically designed office landscape. Appl Ergon. 2008;39(3):284-95.

15. Roche L, Dewey E, Littlefair P. Occupant reactions to daylight in offices. Lighting Res Technol. 2000;32(3):119-26.

16. Ranjbarian M. Designing lighting systems in Industrial Premises. 1st edTehran: Dibagaran Artistic and Cultural Instatement; 2001.

17. Illuminating Engineering Society.. IES Lighting Handbook. 8th edNew York: Illuminating Engineering Society; 1990.

18. Illuminating Engineering Society. IES Lighting Handbook. 3rd ed-
New York: Illuminating Engineering Society; 1980.

19. Sergisian H. Introduction of Lamps and Illumination.Tehran: Dibagaran Artistic and Cultural Instatement; 2001

20. Golmohamadi R, editor. Assessment of Industrial Indoor Lighting.; Proceeding of the International Congress of Iran Occupational Heath..2002; Hamadan, Iran.

21. Akbari J, Dehghan H, Azmoon H, Forouharmajd F. Relationship between lighting and noise levels and productivity of the occupants in automotive assembly industry. J Environ Public Health. 2013;2013:527078.

22. ACGIH., editor. TLVs $®$ and BEIs $₫$ based on the documentation of the threshold limit values for chemical substances and physical agents \& biological exposure indices.; American Conference of Governmental Industrial Hygienists (ACGIH)..2003; Cincinnati.

23. OSHA.. OSHA Technical Manual: Heat Stress.: Occupational Safety Health Administration Directorate of Technical Support; 1991.

24. Zoeshtiyagh P. Illuminating Engineering. 1st edTehran: Publication Company; 2000.

25. Javan M, Barakat S, Dehghan H, Yosefi HA, Amiri M, Abram F. Evaluation of Lighting Intensity in Dormitory Study Halls of Isfahan University of Medical Sciences, Iran. J Health Syst Res. 2013;9(1):96-103.

26. Boyce P, Hunter C, Howlett O. The benefits of daylight through windows. New York: Rensselaer Polytechnic Institute; 2003.

27. Vahedi A, Dianat I. Employees' perception of lighting conditions in manufacturing plants: associations with illuminance measurements.J Res Health Sci. 2014;14(1):40-5.

28. Espinoza LA, Monge-Najera J. Lighting and noise level in the central facilities of the Costa Rican Distance Education University and Elementary Classrooms in Campina Grande, Brazil. J Social Sci. 2010;3(3):106-9.

29. Bridger RS. Introduction to Ergonomics. 2nd edLondon: Taylor and Francis; 2008. 